\title{
Effectiveness of dienogest in improving quality of life in Asian women with endometriosis (ENVISIOeN): interim results from a prospective cohort study under real- life clinical practice
}

Kitirat Techatraisak', Andon Hestiantoro², Soon Ruey ${ }^{3}$, Maria Jesusa Banal-Silao ${ }^{4}$, Mee-Ran Kim ${ }^{5}$, Seok Ju Seong ${ }^{6}$, Syarief Thaufik ${ }^{7}$, Christiane Ahlers ${ }^{8}$, So Young Shin ${ }^{9}$ and Byung Seok Lee ${ }^{10^{*}}$ (D)

\begin{abstract}
Background: Dienogest has been shown to substantially improve endometriosis-associated symptoms such as debilitating chronic pelvic pain, and in turn, health-related quality of life (HRQoL). To date, there is no data on patient-reported outcomes reflecting the real-world practice in Asia where endometriosis is a relevant health, social and economic burden. This non-interventional, multi-center, prospective study aims to investigate the influence of dienogest on HRQOL.

Methods: Asian women received dienogest ( $2 \mathrm{mg} /$ daily) and were followed for 24 months. The effectiveness of dienogest to improve HRQoL and endometriosis-associated pelvic pain (EAPP) was assessed by patient-reported outcomes. HRQoL, especially the "pain" domain as primary endpoint, was evaluated with the Endometriosis Health Profile-30 (EHP-30) questionnaire. The numeric rating scale served to determine changes in the severity of EAPP. Within the presented interim analysis (data cut-off: 2017-11-27), the mean changes in EHP-30 and EAPP scores from baseline to 6 months upon availability of the data were evaluated. Treatment-emergent adverse events (TEAEs) and bleeding profiles were documented.
\end{abstract}

Results: Dienogest therapy decreased EHP-30 scores in all assessed domains (score 0-100, lower scores indicate better HRQoL). Primarily, the "pain" domain was improved in 78.4\% of patients. EAPP was reduced (score 0-10, lower scores reflect less pain), highlighted by a mean reduction of the pain score by -4.5 points. Patients with a higher EAPP score at baseline had an increased response to dienogest ( -6.2 points mean change) compared to patients with low baseline EAPP severity ( -1.4 points mean change). Both surgically and clinically diagnosed patients described comparable pain reduction, as well as women with or without prior treatment. Drug-related TEAEs were documented for 31.5\% of patients, with amenorrhoea (5.9\%) and metrorrhagia (5.1\%) being the most common events. The bleeding pattern was changed upon dienogest, characterized by decreased normal bleeding (84.2 to 28.8\%) and increased amenorrhea (3.2 to 42.9\%) at 6 months.

\footnotetext{
* Correspondence: DR222@yuhs.ac

${ }^{10}$ Division of Gynecologic Endocrinology and Infertility, Department of

Obstetrics and Gynecology, Severance Hospital,Yonsei University, 50-1

Yonsei-ro, Seodaemun-gu, 120-752 Seoul, Republic of Korea

Full list of author information is available at the end of the article
}

(c) The Author(s). 2019 Open Access This article is distributed under the terms of the Creative Commons Attribution 4.0 International License (http://creativecommons.org/licenses/by/4.0/), which permits unrestricted use, distribution, and reproduction in any medium, provided you give appropriate credit to the original author(s) and the source, provide a link to the Creative Commons license, and indicate if changes were made. The Creative Commons Public Domain Dedication waiver (http://creativecommons.org/publicdomain/zero/1.0/) applies to the data made available in this article, unless otherwise stated. 
(Continued from previous page)

Conclusion: The data indicate an amelioration of HRQoL and EAPP upon dienogest therapy. No new safety signals were observed. Therefore, its use as first-line therapy for long-term management of debilitating and chronic endometriosis-associated pain represents an interesting option that remains to be further investigated.

Trial registration: Name of registry: Clinical Trials Clinicaltrials.gov registration number: NCT02425462 Registration date: 2015-04-24. Registration timing: prospective.

Keywords: Endometriosis, Health-related quality of life, Pain, Asian women, Clinical diagnosis,

\section{Background}

Endometriosis is a chronic disease that affects approximately $10 \%$ of all women in reproductive age and up to $50 \%$ of infertile women $[1,2]$. Current knowledge of various aspects of endometriosis is based on data primarily obtained from a Caucasian population; however there is scarce evidence among Asian women, where the prevalence of endometriosis appears to be increased compared to Caucasian women. Several studies reported an up to nine-fold increase in risk in Asian women as compared to the white female population [2-5].

Endometriosis is characterized by endometrial-like tissue outside the uterus. Conventionally, diagnosis of endometriosis required the combination of laparoscopic inspection of the pelvis with histological verification of endometrial glands, but this recommendation is not supported by robust evidence [6-8].

Guidelines recommend a non-invasive clinical diagnosis based on clinical symptoms and patients history $[1,6$, 7]. However, as endometriosis symptoms appear non-specifically, the gap between the first symptoms and precise diagnosis ranges from four to 10 years [6]. In China, diagnosis is delayed on average even by 13 years [9]. Currently, there is no cure for endometriosis; rather, it is characterized by a progressive course with worsened symptoms if no appropriate therapy is applied [10]. In order to minimize disease progression, especially in women who wish to maintain their fertility, early diagnosis and proactive treatment is of big importance. Surgical intervention can substantially reduce pain and may increase fertility, but there is an increased risk of recurrence $(40-50 \%$ at 5 years) and re-operation [11, 12]. Moreover, time to surgery can hinder appropriate treatment. Consequently, the current guidelines recommend a life-long, adapted management characterized by maximum medical treatment and prevention of repeated surgical procedures [7, 10]. In Asian countries, empirical medical treatment prior to or even without surgical intervention is widely practiced [9].

Classic endometriosis symptoms are chronic pelvic pain, dysmenorrhea, dyspareunia and infertility; furthermore, endometriosis can cause symptoms arising from other organs involved, such as dyschezia, tenesmus and dysuria and/or hematuria [13]. Quality of life studies reveal that endometriosis symptoms, especially chronic pelvic pain, can influence several aspects of a woman's life, such as work, education, relationship, social support, especially with increasing severity of symptoms [10]. The impact of the disease on psychosocial parameters can lead to a significant reduction in health-related quality of life (HRQoL); thus, effective treatment of chronic pelvic pain is essential [10]. Nonsteroidal anti-inflammatory drugs, oral contraceptives and progestins are commonly considered first-line treatment for patients with endometriosis-associated pain [6, 10]. Dienogest is an oral progestin with a relatively short plasma half-life of approximately 9-10 $\mathrm{h}$ and high oral bioavailability of $>90 \%$, offering unique pharmacologic benefits such as potent progestogenic effects that in turn result in pronounced endometrial lesion reduction. Furthermore, it is characterized by moderate suppression of gonadotropin secretion, anti-androgenic and anti-proliferative effects as well as good tolerability, rendering it an attractive long-term therapeutic approach $[10,14]$. Importantly, dienogest demonstrated comparable efficacy with gonadotropin-releasing hormone $(\mathrm{GnRH})$ agonists in reducing EAPP in clinical trials and is meanwhile approved for the treatment of endometriosis in 157 countries worldwide, including 15 in Asia [15, 16].

To date, the impact of dienogest treatment on quality of life has not been extensively studied in the real-life setting. Moreover, most of the clinical trials on dienogest enrolled only women with definite surgical diagnosis of endometriosis. This international non-interventional, non-controlled, multi-center, prospective cohort study (ENVISIOeN) aims to assess the effectiveness of dienogest (trade name VISANNE ${ }^{\oplus}$, Bayer AG, Berlin, Germany) in improving HRQoL in clinically and surgically diagnosed Asian women with endometriosis under routine clinical practice. The interim analysis evaluated the pain domain of HRQoL as primary goal, as well as EAPP and safety as secondary goals after 6 months of follow up.

\section{Methods}

\section{Study design}

The study was carried out at 36 sites in Thailand (five centres), Indonesia (ten centres), Republic of Korea (twelve centres), Malaysia (four centres), Philippines (three centres) and Singapore (two centres) in 
accordance with the amended version of the Declaration of Helsinki (Oct 2013) and complied with Good Clinical Practice. For more information, see Clinicaltrials.gov (NCT02425462).

\section{Patients}

The inclusion criteria were: Asian female $\geq 18$ years old; clinical or surgical diagnosis of endometriosis; presence of EAPP; uninfluenced decision taken by the physician to newly prescribe dienogest; written informed consent. Women were excluded in case of participation in an investigational program with interventions outside of routine clinical practice; any contraindication listed in the local summary of product characteristics. All eligible patients were treated according to standard medical guidelines or usual care of the participating institute.

\section{Visits}

The observation period of 24 months for each patient enrolled in this study consisted of the treatment phase and, in case of discontinuation of the treatment, the follow up period. Subjects were followed whether or not they remained on the treatment with dienogest. Information on the date and reasons for discontinuation were collected.

\section{Effectiveness variables}

The primary endpoint was to assess the effectiveness of dienogest to change HRQoL with special attention to the dimension of pain. Patients were asked to complete the Endometriosis Health Profile-30 (EHP-30) at baseline and at the visits 6 months after start of treatment. The EHP-30 is a disease-specific, reliable and valid instrument to measure the effects of endometriosis on HRQoL, especially on physical, psychologic and social aspects, from the patients' perspective, as described previously [17-19]. Secondary effectiveness endpoint variables comprised the assessment of changes in the other core as well as modular HRQoL domains and changes in the severity of EAPP from baseline to 6-months visits measured by patient-reported numeric rating scale (NRS) with a 4-week recall period at every visit.

\section{Safety variables}

All TEAEs, including the ones leading to discontinuation were recorded at each visit throughout the study and summarized using the MedDRA coding system (not to be confused with the bleeding profile terminology). The bleeding profile was evaluated based on the following categories (definition within the figure): normal bleeding, irregular bleeding cycle, amenorrhea, intermenstrual bleeding/spotting. Further secondary endpoints analyzed within the scope of the interim analysis were continuation rate as well as patients' and physicians' satisfaction rate.

\section{Data sources and measurement}

The treating physician collected historical data (demographic and clinical characteristics) from medical records if available and treatment-related data during visits that took place in routine practice.

\section{Bias}

To circumvent the general bias susceptibility inherent to observational studies, e.g. selection bias, it ensured that the study population represented routine patient profiles treated with dienogest in Asia. The patients were selected only based on inclusion and exclusion criteria in a consecutive manner.

\section{Study size}

The calculation of the sample size focused on the pain dimension in the EHP-30 score. Assumptions for the sample size have been based on earlier studies that collected information on quality of life in patients with endometriosis who have been treated daily with a progestin [20]. For this planned study similar results were expected. With a sample size of 696 subjects the 2-sided 99\% confidence interval was expected to extend at most nominal $+/-2.25$ in the score (which corresponds to $+/-4.5 \%$ of the expected mean change) with a probability of $95 \%$. With a drop-out rate of about $20 \%$ it was advisable to include at least 870 subjects into this study.

In terms of safety this study was sufficiently large to capture uncommon adverse events. With the planned sample size at least one adverse event with a relative frequency of $0.3 \%$ was expected to be observed with a probability of $90 \%$.

\section{Statistical analysis}

Effectiveness analyses were conducted on the efficacy analysis set (EFF) that included all patients with evaluable EHP-30 questionnaire at baseline and at least one evaluable EHP-30 questionnaire post-baseline between week 12 and 36 after start of treatment. Measurements after discontinuation of treatment were excluded. Safety analyses were performed on the full analysis set (FAS) and comprised all patients that took at least one dose of dienogest.

The HRQoL parameters were assessed as described previously. The score ranged between 0 (best health status) and 100 (worst health status) [18]. For EAPP measured by patient-reported NRS, the patients were asked to circle one number in a range between 0 , referring to "absence of pain" and 10, corresponding to "unbearable pain". Changes in the severity of EAPP from baseline visit to 6-months visit, measured by patient-reported 
NRS at every visit were evaluated overall and separately for subgroups stratified by baseline severity of EAPP, use of rescue medication, prior treatment and method of diagnosis. The patient numbers for the conducted analyses vary due to variable numbers of complete and evaluable questionnaires, especially for analyses of mean changes.

The analysis was primarily of explorative and descriptive nature. All variables were analyzed descriptively with appropriate statistical methods. SAS release 9.4 (SAS Institute, Cary, NC, USA) was used for data analysis. Continuous variables were described by visit (baseline and 6-months) and as mean change from baseline to 6 months for each item of the questionnaire, if applicable. For change from baseline in EHP-30 scores descriptive statistics as well as confidence intervals have been provided. Frequency distributions of patients with improvement, deterioration or no change in EHP-30 and EAPP scores were summarized. Missing data was not replaced and was given as "missing" in the tables. All adverse events were presented within incidence tables as preferred terms by system organ class. The descriptive analysis of adverse events was the basis to assess tolerability and safety of dienogest in the study population. The analyses described were performed on TEAEs. Non TEAEs were tabulated without further stratification. Partially missing TEAE onset dates were imputed following a worst case approach. The earliest possible date was used (as described above), but in case the $\mathrm{AE}$ onset could be before or after start of dienogest, TEAE onset was imputed by the first day of dienogest treatment.

\section{Results}

\section{Patient disposition and characteristics}

Overall, a total of 895 patients were enrolled at 36 sites from $04 / 2015$ to $08 / 2016$. The FAS comprised 865 patients who were eligible, gave their informed consent and took at least one dose of dienogest. Furthermore, 510 patients with evaluable primary outcome were included into the EFF. The mean \pm SD duration of treatment with end of observation was $14.1 \pm 7.5$ months ( $n$ = 97 evaluable patients; EFF). Leading reasons for end of observation were patient lost to follow-up $(n=37 / 97$; $38.1 \%)$ and regular end of study ( $n=35 / 97 ; 36.1 \%$ ).

Baseline characteristics are summarized in Table 1. The most common symptoms of endometriosis were dysmenorrhea $(n=684 / 865 ; 79.1 \%)$ and chronic pelvic pain $(n=279 / 865 ; 32.3 \%)$. While endometriosis was diagnosed within 1 year before initial visit in the majority of the patients $(n=644 / 864 ; 74.5 \%)$, only less than half of the women reported onset of first symptoms within this time span $(n=402 / 865 ; 46.2 \%)$. Moreover, $29.9 \%$ of women $(n=259 / 865)$ documented appearance of first symptoms between one and 5 years before and $23.0 \%$ ( $n$
Table 1 Baseline characteristics (to be placed after line 240)

\begin{tabular}{|c|c|c|}
\hline \multicolumn{3}{|l|}{ Parameter } \\
\hline Demography & $\mathrm{n}$ & $\begin{array}{l}\text { years, mean } \pm \\
\text { SD }\end{array}$ \\
\hline Age at registration & 865 & $34.4 \pm 7.6$ \\
\hline History of endometriosis $(n=865)$ & $\mathrm{n}$ & $\%$ women \\
\hline \multicolumn{3}{|l|}{ Onset of first symptoms ${ }^{a}$} \\
\hline$<1$ year ago & 402 & 46.5 \\
\hline Between 1 and 5 years ago & 259 & 29.9 \\
\hline$>5$ years ago & 199 & 23.0 \\
\hline Missing & 5 & 0.6 \\
\hline \multicolumn{3}{|l|}{ Most common symptoms of endometriosis ${ }^{b}$} \\
\hline Dysmenorrhea & 684 & 79.1 \\
\hline Chronic pelvic pain & 279 & 32.3 \\
\hline Dyspareunia & 51 & 5.9 \\
\hline \multicolumn{3}{|l|}{ Timepoint of first diagnosis ${ }^{a}$} \\
\hline$<1$ year ago & 644 & 74.5 \\
\hline Between 1 and 5 years ago & 135 & 15.6 \\
\hline$>5$ years ago & 85 & 9.8 \\
\hline Missing & 1 & 0.1 \\
\hline \multicolumn{3}{|l|}{ Methods of diagnosis } \\
\hline Surgical diagnosis & 616 & 71.2 \\
\hline Clinical diagnosis only & 247 & 28.6 \\
\hline Missing & 2 & 0.2 \\
\hline \multicolumn{3}{|l|}{ Endometriosis lesions ( $n=768$ evaluable patients) } \\
\hline Single & 417 & 54.3 \\
\hline Multi & 351 & 45.7 \\
\hline \multicolumn{3}{|l|}{ Endometriosis localization ${ }^{2}$} \\
\hline Ovary & 640 & 88.4 \\
\hline Pelvic organ & 282 & 39.0 \\
\hline Extra pelvic & 21 & 2.9 \\
\hline r-ASRM stage of endometriosis $(n=246)^{c}$ & $\mathrm{n}$ & $\%$ women \\
\hline Stage I (minimal) & 17 & 6.9 \\
\hline Stage II (mild) & 20 & 8.1 \\
\hline Stage III (moderate) & 86 & 35.0 \\
\hline Stage IV (severe) & 126 & 51.2 \\
\hline Most common previous diseases $(n=141)^{2}$ & $\mathrm{n}$ & $\%$ women \\
\hline Uterine leiomyoma & 69 & 48.9 \\
\hline Endometrial polyp & 36 & 25.5 \\
\hline Ovarian cysts & 26 & 18.4 \\
\hline Pelvic inflammatory disease & 20 & 14.2 \\
\hline Most common concomitant diseases $(n=146)^{2}$ & $\mathrm{n}$ & $\%$ women \\
\hline Adenomyosis & 46 & 31.5 \\
\hline Uterine leiomyoma & 39 & 26.7 \\
\hline Anemia & 18 & 12.3 \\
\hline Prior endometriosis treatment $(n=864$ & $\mathrm{n}$ & $\%$ women \\
\hline
\end{tabular}

Prior endometriosis treatment $(n=864$ evaluable patients) 
Table 1 Baseline characteristics (to be placed after line 240) (Continued)

\begin{tabular}{lll}
\hline Parameter & & \\
\hline Patients with prior treatment & 514 & 59.5 \\
Patients without prior treatment & 350 & 40.5 \\
Type of treatment $(n=514)$ & $\mathrm{n} \quad \%$ women \\
Surgery & 449 & 87.4 \\
Hormonal treatment & 179 & 34.8 \\
Pain therapy & 89 & 17.3 \\
\hline
\end{tabular}

${ }^{a}$ Partially missing dates were imputed by the earliest possible time point: In case that only the day was missing, the date was imputed as the first day of the month. In case that the day and the month were missing, i.e. only the year was available the day and month was imputed by January 1 st. ${ }^{2}$ Multiple answers possible. 'Assessed during surgical treatment; 3 patients underwent repeated surgery

$=199 / 865)$ more than 5 years before. In fact, $24.6 \%$ of patients diagnosed within 1 year before initial visit experienced their first symptoms $1-5$ years earlier and $12.4 \%$ of patients even $>5$ years before, amounting to approximately $37 \%$ of patients with delayed diagnosis of endometriosis. The time period from appearance of first symptoms to first diagnosis tended to be shorter in surgically diagnosed patients than in patients with clinical only diagnosis (mean, $21.3 \pm 43.9$ months vs. $29 \pm 44.8$ months, respectively). The majority of women $(n=449$ / $514 ; 87.4 \%$ ) underwent prior surgery to treat endometriosis-associated pain. The proportion of women with pain recurrence despite surgical treatment was $27.4 \%(n=123 / 449)$ and the mean \pm SD duration until pain recurrence after surgery was $19.3 \pm 21.0$ months (duration was evaluable for 114 women). A total of 179 women received previous hormonal treatment, with $56.4 \%$ of those women $(n=101 / 179)$ suffering from pain recurrence after a mean \pm SD time of $9.9 \pm 13.9$ months (evaluable for 97 women). Pain medications were given to 89 patients (of 514 with prior endometriosis treatment; $17.3 \%$ ), predominantly $2-3$ days per week $(n=50 / 89 ; 56.2 \%)$, with a mean \pm SD pain recurrence after $11.9 \pm 37.2$ days (evaluable for 79 patients) after or during pain therapy.

\section{Effectiveness variables}

\section{Primary effectiveness variable}

Table 2 summarizes the EHP-30 score distribution in the domains of the core questionnaire at baseline visit and 6-months visit, as well as the changes from baseline. The mean time \pm SD point of measurement was $177.3 \pm$ 22.1 days ( $\mathrm{n}$ total $=444$ ). Overall, the HRQoL nominally improved with regard to all reported domains at the 6-months visit compared to the baseline visit. Treatment with dienogest elicited a mean change \pm SD of $-28.4 \pm$ 27.3 (pain; 95\%-CI: -31;-25.9), followed by mean \pm SD changes of $-23.9 \pm 27.9$ (control; 95\%-CI: -26.5;-21.3), $14.7 \pm 26.6$ (emotional well-being; 95\%-CI: -17.2;-12.3), $-12.9 \pm 26.3$ (social support; 95\%-CI: -15.3;-10.4) and $7.7 \pm 25.6$ (self-image; 95\%-CI: -10.1;-5.3). Basically, dienogest treatment had the greatest impact on the dimensions of pain and control (Fig. 1). The proportion of patients with improvement of the pain score after 6 months was $78.4 \%(n=348)$, whereas $14.0 \%(n=62)$ showed no change and $7.7 \%(\mathrm{n}=34)$ reported deterioration. In the control domain, $70.5 \%(n=313)$ of women experienced an improvement, whereas $18.2 \% \quad(n=81)$ and $10.8 \%(n=48 / 444)$ had no change or deterioration, respectively. In the domains of emotional well-being,

Table 2 EHP-30 core scores and changes from baseline (to be placed after line 259)

\begin{tabular}{|c|c|c|c|c|c|c|c|c|c|c|c|c|}
\hline Dimension & Timepoint & $\mathrm{N}$ & mean & Std & Q1 & Median & Q3 & Min & Max & Nmiss & Cl 95\% & $\mathrm{Cl} 95 \%$ \\
\hline \multirow[t]{3}{*}{ Pain } & Baseline & 510 & 35.65 & 27.57 & 9.09 & 34.09 & 54.55 & 0.00 & 100.00 & 0 & - & \\
\hline & 6 months & 444 & 7.98 & 13.20 & 0.00 & 0.00 & 12.50 & 0.00 & 65.91 & 0 & - & \\
\hline & Change from baseline & 444 & -28.44 & 27.33 & -47.73 & -25.00 & -4.55 & -100 & 36.36 & 0 & -30.99 & -25.89 \\
\hline \multirow[t]{3}{*}{ Control and powerlessness } & Baseline & 509 & 34.39 & 27.94 & 8.33 & 33.33 & 54.17 & 0.00 & 100.00 & 1 & - & \\
\hline & 6 months & 443 & 10.92 & 15.65 & 0.00 & 4.17 & 16.67 & 0.00 & 87.50 & 1 & - & \\
\hline & Change from baseline & 442 & -23.86 & 27.89 & -41.67 & -16.67 & 0.00 & -100.00 & 50.00 & 2 & -26.47 & -21.25 \\
\hline \multirow[t]{3}{*}{ Emotional well-being } & Baseline & 508 & 31.85 & 25.42 & 8.33 & 29.17 & 50.00 & 0.00 & 100.00 & 2 & - & \\
\hline & 6 months & 443 & 17.26 & 20.62 & 0.00 & 8.33 & 29.17 & 0.00 & 91.67 & 1 & - & \\
\hline & Change from baseline & 442 & -14.73 & 26.55 & -33.33 & -8.33 & 0.00 & -100.00 & 79.17 & 2 & -17.22 & -12.25 \\
\hline \multirow[t]{3}{*}{ Social support } & Baseline & 509 & 26.98 & 25.21 & 0.00 & 25.00 & 43.75 & 0.00 & 100.00 & 1 & - & \\
\hline & 6 months & 443 & 14.25 & 19.95 & 0.00 & 0.00 & 25.00 & 0.00 & 87.50 & 1 & - & \\
\hline & Change from baseline & 443 & -12.85 & 26.32 & -31.25 & -6.25 & 0.00 & -100.00 & 87.50 & 1 & -15.31 & -10.39 \\
\hline \multirow[t]{3}{*}{ Self-image } & Baseline & 509 & 19.97 & 24.06 & 0.00 & 8.33 & 33.33 & 0.00 & 100.00 & 1 & - & \\
\hline & 6 months & 443 & 11.87 & 19.38 & 0.00 & 0.00 & 16.67 & 0.00 & 91.67 & 1 & - & \\
\hline & Change from baseline & 443 & -7.67 & 25.58 & -16.67 & 0.00 & 0.00 & -100.00 & 91.67 & 1 & -10.06 & -5.29 \\
\hline
\end{tabular}




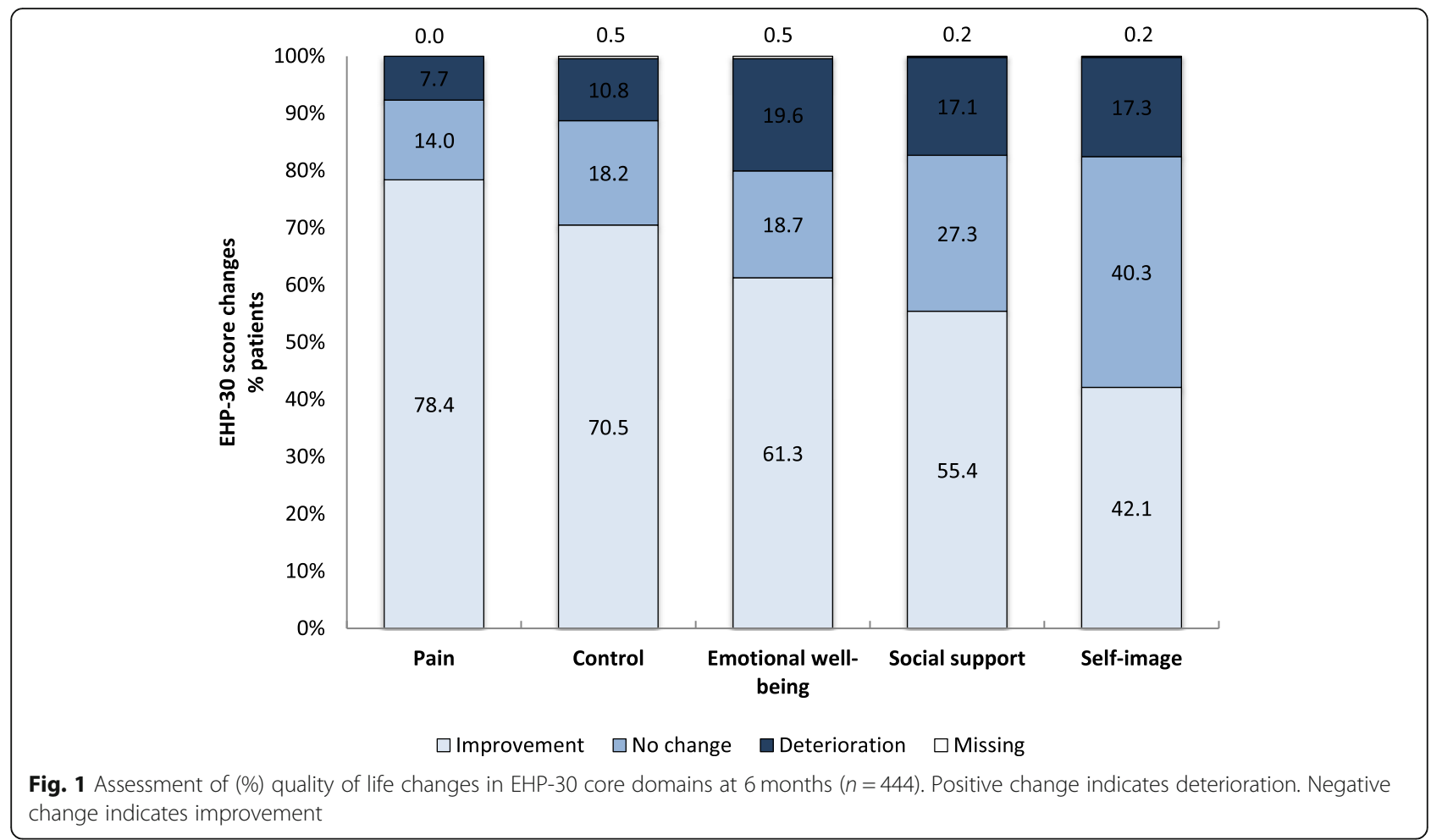

social support and self-image, $61.3 \%(n=272), 55.4 \%(n$ $=256)$ and $42.1 \%(n=187)$ of patients reported improvement, respectively.

\section{Secondary effectiveness variables}

Baseline and 6-months visit EHP-30 scores as well as changes within the modular questionnaire are summarized in Table 3. There, the domain of work was most changed upon dienogest therapy. The mean relative study day \pm SD for the EHP-30 modular questionnaire was $177.5 \pm 21.9(n=440)$. In the domain of work, the mean change \pm SD was $-21.8 \pm 25.3$. Mean changes \pm SD in other domains were as follows: $-19.5 \pm 29.8$ (relationship with children), $-11.4 \pm 25.2$ (sexual intercourse), $-7.2 \pm$ 22.2 (treatment) and $-8.6 \pm 21.7$ (infertility).

With regard to the EAPP assessment, the mean relative study day \pm SD was $175 \pm 23.4(n=434)$. The total study population reported a mean change \pm SD of -4.5

Table 3 EHP-30 modular scores and changes from baseline (to be placed after line 267)

\begin{tabular}{|c|c|c|c|c|c|c|c|c|c|c|c|c|}
\hline Dimension & Timepoint & $\mathrm{N}$ & mean & Std & Q1 & Median & Q3 & Min & Max & Nmiss & Cl 95\% & Cl 95\% \\
\hline \multirow[t]{3}{*}{ Work } & Baseline & 447 & 29.41 & 27.02 & 5.00 & 25.00 & 50.00 & 0.00 & 100.00 & 8 & - & - \\
\hline & 6 months & 398 & 7.01 & 13.05 & 0.00 & 0.00 & 10.00 & 0.00 & 70.00 & 5 & - & - \\
\hline & Change from baseline & 366 & -21.76 & 25.31 & -40.00 & -15.00 & 0.00 & -90.00 & 40.00 & 76 & -24.36 & -19.16 \\
\hline \multirow[t]{3}{*}{ Relationship with children } & Baseline & 176 & 24.57 & 29.76 & 0.00 & 0.00 & 50.00 & 0.00 & 100.00 & 25 & - & - \\
\hline & 6 months & 174 & 5.24 & 13.45 & 0.00 & 0.00 & 0.00 & 0.00 & 75.00 & 25 & - & - \\
\hline & Change from baseline & 130 & -19.52 & 29.82 & -50.00 & 0.00 & 0.00 & -100.00 & 50.00 & 312 & -24.69 & -14.35 \\
\hline \multirow[t]{3}{*}{ Sexual intercourse } & Baseline & 325 & 26.34 & 25.50 & 0.00 & 20.00 & 45.00 & 0.00 & 100.00 & 75 & - & - \\
\hline & 6 months & 278 & 14.93 & 20.82 & 0.00 & 2.50 & 25.00 & 0.00 & 95.00 & 34 & - & - \\
\hline & Change from baseline & 238 & -11.42 & 25.23 & -25.00 & -5.00 & 0.00 & -90.00 & 75.00 & 204 & -14.64 & -8.20 \\
\hline \multirow[t]{3}{*}{ Treatment } & Baseline & 361 & 19.25 & 22.37 & 0.00 & 16.67 & 33.33 & 0.00 & 100.00 & 27 & - & - \\
\hline & 6 months & 421 & 10.83 & 16.00 & 0.00 & 0.00 & 16.67 & 0.00 & 83.33 & 6 & - & - \\
\hline & Change from baseline & 307 & -7.19 & 22.18 & -16.67 & 0.00 & 0.00 & -91.67 & 50.00 & 135 & -9.68 & -4.70 \\
\hline \multirow[t]{3}{*}{ Infertility } & Baseline & 303 & 27.97 & 28.47 & 0.00 & 18.75 & 50.00 & 0.00 & 100.00 & 29 & - & - \\
\hline & 6 months & 290 & 19.53 & 24.23 & 0.00 & 12.5 & 31.25 & 0.00 & 100.00 & 19 & - & - \\
\hline & Change from baseline & 224 & -8.62 & 21.74 & -18.75 & 0.00 & 0.00 & -100.00 & 56.25 & 218 & -11.48 & -5.76 \\
\hline
\end{tabular}


\pm 3.0 (Table 4; $n=402)$. Remarkably, $84.3 \%(n=366)$ of the total patient population described an improvement of EAPP with dienogest therapy, whereas 5.5\% $(n=24)$ and $2.8 \%(n=12)$ reported no change or even deterioration, respectively (Fig. 2). In line with the previous findings, baseline severity of EAPP had influenced patients' pain reduction, as $92.5 \%(259 / 280)$ of women with EAPP baseline severity $>4$ vs. $71.3 \%(n=107 / 150)$ of women with EAPP baseline severity $\leq 4$ experienced an amelioration of EAPP (Fig. 2a). Patients with EAPP baseline severity $>4$ nominally had a greater benefit (mean change \pm SD: $-6.2 \pm 2.1 ; n=261$ ) compared to women with baseline severity $\leq 4$ (mean change \pm SD: $-1.4 \pm 1.7 ; n=$ 141; Table 4). The type of diagnosis had no obvious influence on the effectiveness of dienogest to alleviate EAPP. The mean changes \pm SD of $-4.3 \pm 2.9(n=305)$ and $-5.1 \pm 3.2(n=97)$ for surgically and clinically only diagnosed patients, respectively, were comparable to the mean change of the total population (Table 4). This was reflected by similar improvement rates of $84.0 \%(n=$ $279 / 332)$ in surgically diagnosed patients vs. $85.3 \%(n=$ $87 / 102$ ) in clinically only diagnosed patients (Fig. 2b). Patients who took rescue medication at baseline showed a tendency towards an improved benefit from dienogest,

Table 4 EAPP scores and changes from baseline stratified by groups (to be placed after line 289)

\begin{tabular}{|c|c|c|c|c|c|c|c|c|c|c|c|}
\hline Category & Stratification & Timepoint & $\mathrm{N}$ & mean & Std & Q1 & Median & Q3 & Min & Max & Nmiss \\
\hline \multirow[t]{3}{*}{ Total } & & Baseline & 505 & 5.48 & 2.75 & 3.00 & 6.00 & 8.00 & 0.00 & 10.00 & 5 \\
\hline & & 6 months & 405 & 0.97 & 1.43 & 0.00 & 0.00 & 2.00 & 0.00 & 7.00 & 29 \\
\hline & & $\begin{array}{l}\text { Change from } \\
\text { baseline }\end{array}$ & 402 & -4.50 & 2.99 & -7.00 & -5.00 & -2.00 & -10.00 & 4.00 & 32 \\
\hline \multirow[t]{6}{*}{ Method of diagnosis } & \multirow[t]{3}{*}{ Surgical diagnosis ${ }^{a}$} & Baseline & 388 & 5.30 & 2.75 & 3.00 & 6.00 & 7.00 & 0.00 & 10.00 & 3 \\
\hline & & 6 months & 306 & 0.96 & 1.35 & 0.00 & 0.00 & 2.00 & 0.00 & 7.00 & 26 \\
\hline & & $\begin{array}{l}\text { Change from } \\
\text { baseline }\end{array}$ & 305 & -4.31 & 2.92 & -7.00 & -4.00 & -2.00 & -10.00 & 4.00 & 27 \\
\hline & \multirow[t]{3}{*}{ Clinical only diagnosis } & Baseline & 117 & 6.05 & 2.71 & 4.00 & 6.00 & 8.00 & 0.00 & 10.00 & 2 \\
\hline & & 6 months & 99 & 1.01 & 1.66 & 0.00 & 0.00 & 1.00 & 0.00 & 6.00 & 3 \\
\hline & & $\begin{array}{l}\text { Change from } \\
\text { baseline }\end{array}$ & 97 & -5.09 & 3.16 & -8.00 & -5.00 & -3.00 & -10.00 & 4.00 & 5 \\
\hline \multirow[t]{6}{*}{ Baseline severity of EAPP } & \multirow[t]{3}{*}{ Baseline severity of EAPP $\leq 4$} & Baseline & 176 & 2.28 & 1.19 & 1.00 & 2.50 & 3.00 & 0.00 & 4.00 & 0 \\
\hline & & 6 months & 141 & 0.81 & 1.29 & 0.00 & 0.00 & 1.00 & 0.00 & 6.00 & 9 \\
\hline & & $\begin{array}{l}\text { Change from } \\
\text { baseline }\end{array}$ & 141 & -1.44 & 1.66 & -3.00 & -1.00 & -1.00 & -4.00 & 4.00 & 9 \\
\hline & \multirow[t]{3}{*}{ Baseline severity of EAPP $>4$} & Baseline & 329 & 7.19 & 1.57 & 6.00 & 7.00 & 8.00 & 5.00 & 10.00 & 0 \\
\hline & & 6 months & 261 & 1.05 & 1.48 & 0.00 & 0.00 & 2.00 & 0.00 & 7.00 & 19 \\
\hline & & $\begin{array}{l}\text { Change from } \\
\text { baseline }\end{array}$ & 261 & -6.16 & 2.12 & -8.00 & -6.00 & -5.00 & -10.00 & 1.00 & 19 \\
\hline \multirow{6}{*}{$\begin{array}{l}\text { Previous endometriosis } \\
\text { treatment }\end{array}$} & \multirow{3}{*}{$\begin{array}{l}\text { Previous surgical or hormonal } \\
\text { treatment }\end{array}$} & Baseline & 313 & 5.24 & 2.69 & 3.00 & 6.00 & 7.00 & 0.00 & 10.00 & 0 \\
\hline & & 6 months & 242 & 0.93 & 1.40 & 0.00 & 0.00 & 1.00 & 0.00 & 7.00 & 19 \\
\hline & & $\begin{array}{l}\text { Change from } \\
\text { baseline }\end{array}$ & 242 & -4.35 & 2.83 & -7.00 & -4.00 & -2.00 & -10.00 & 3.00 & 19 \\
\hline & \multirow{3}{*}{$\begin{array}{l}\text { No previous surgical or hormonal } \\
\text { treatment }\end{array}$} & Baseline & 191 & 5.88 & 2.82 & 3.00 & 6.00 & 8.00 & 0.00 & 10.00 & 5 \\
\hline & & 6 months & 163 & 1.04 & 1.48 & 0.00 & 0.00 & 2.00 & 0.00 & 6.00 & 10 \\
\hline & & $\begin{array}{l}\text { Change from } \\
\text { baseline }\end{array}$ & 160 & -4.74 & 3.21 & -7.00 & -5.00 & -2.00 & -10.00 & 4.00 & 13 \\
\hline \multirow[t]{6}{*}{ Use of rescue medication } & \multirow[t]{3}{*}{ Use of rescue medication } & Baseline & 52 & 6.65 & 2.72 & 5.00 & 8.00 & 8.50 & 0.00 & 10.00 & 0 \\
\hline & & 6 months & 42 & 1.29 & 1.86 & 0.00 & 0.00 & 2.00 & 0.00 & 6.00 & 1 \\
\hline & & $\begin{array}{l}\text { Change from } \\
\text { baseline }\end{array}$ & 42 & -5.55 & 3.31 & -8.00 & -6.00 & -4.00 & -10.00 & 4.00 & 1 \\
\hline & \multirow[t]{3}{*}{ No use of rescue medication } & Baseline & 452 & 5.33 & 2.72 & 3.00 & 6.00 & 7.50 & 0.00 & 10.00 & 5 \\
\hline & & 6 months & 362 & 0.94 & 1.37 & 0.00 & 0.00 & 1.00 & 0.00 & 7.00 & 28 \\
\hline & & $\begin{array}{l}\text { Change from } \\
\text { baseline }\end{array}$ & 359 & -4.37 & 2.93 & -7.00 & -4.00 & -2.00 & -10.00 & 3.00 & 31 \\
\hline
\end{tabular}



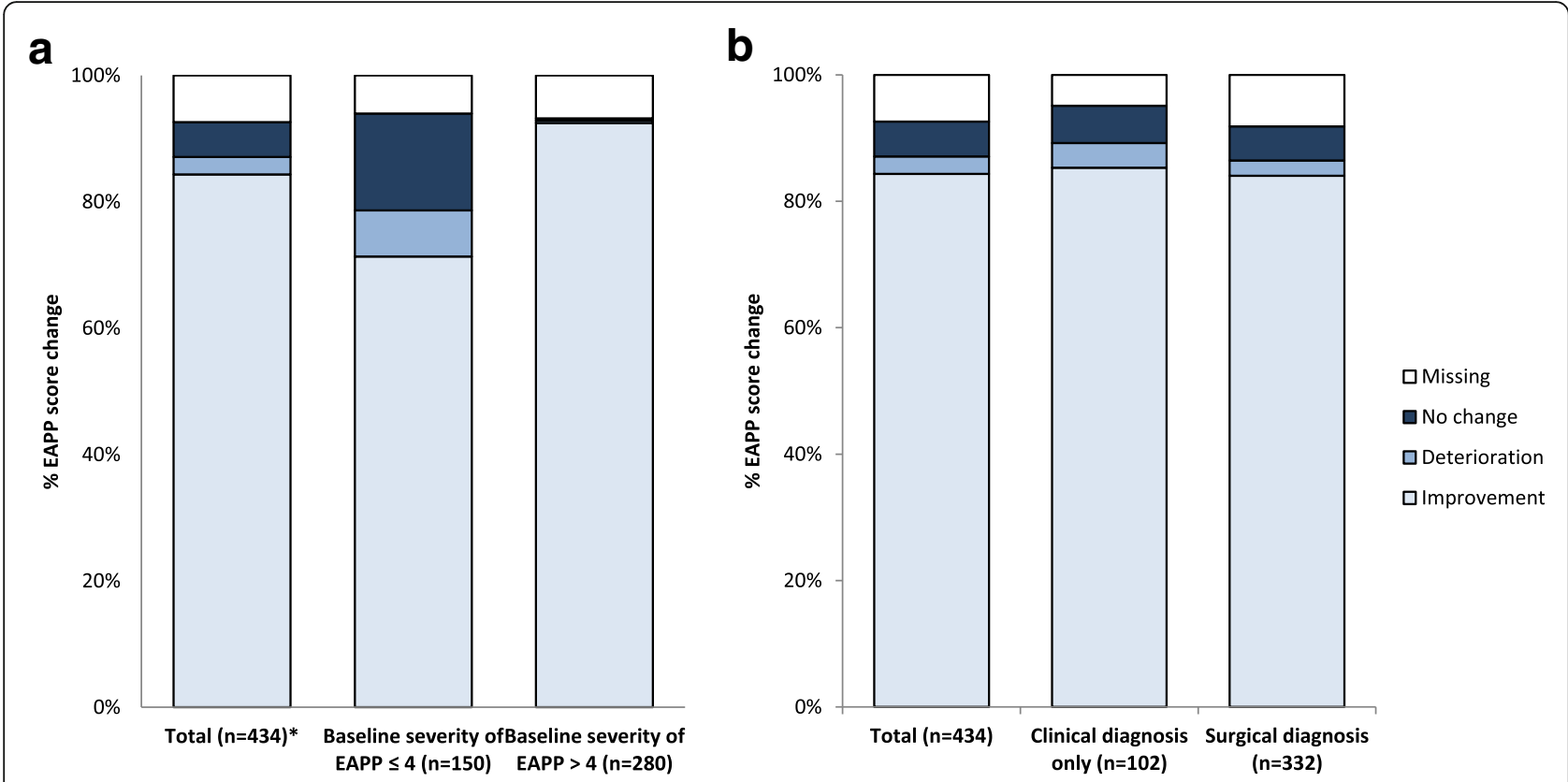

Fig. 2 Evaluation of changes (\%) in endometriosis-associated pelvic pain (EAPP) at 6 months $(n=434)$ according to EAPP baseline severity (a) and type of diagnosis (b). The changes have been assessed by numeric rating scale in a 4-week recall period. Positive change indicates deterioration. Negative change indicates improvement. *Change was not evaluable for four patients due to missing baseline severity of EAPP for three patients and one lost to follow-up

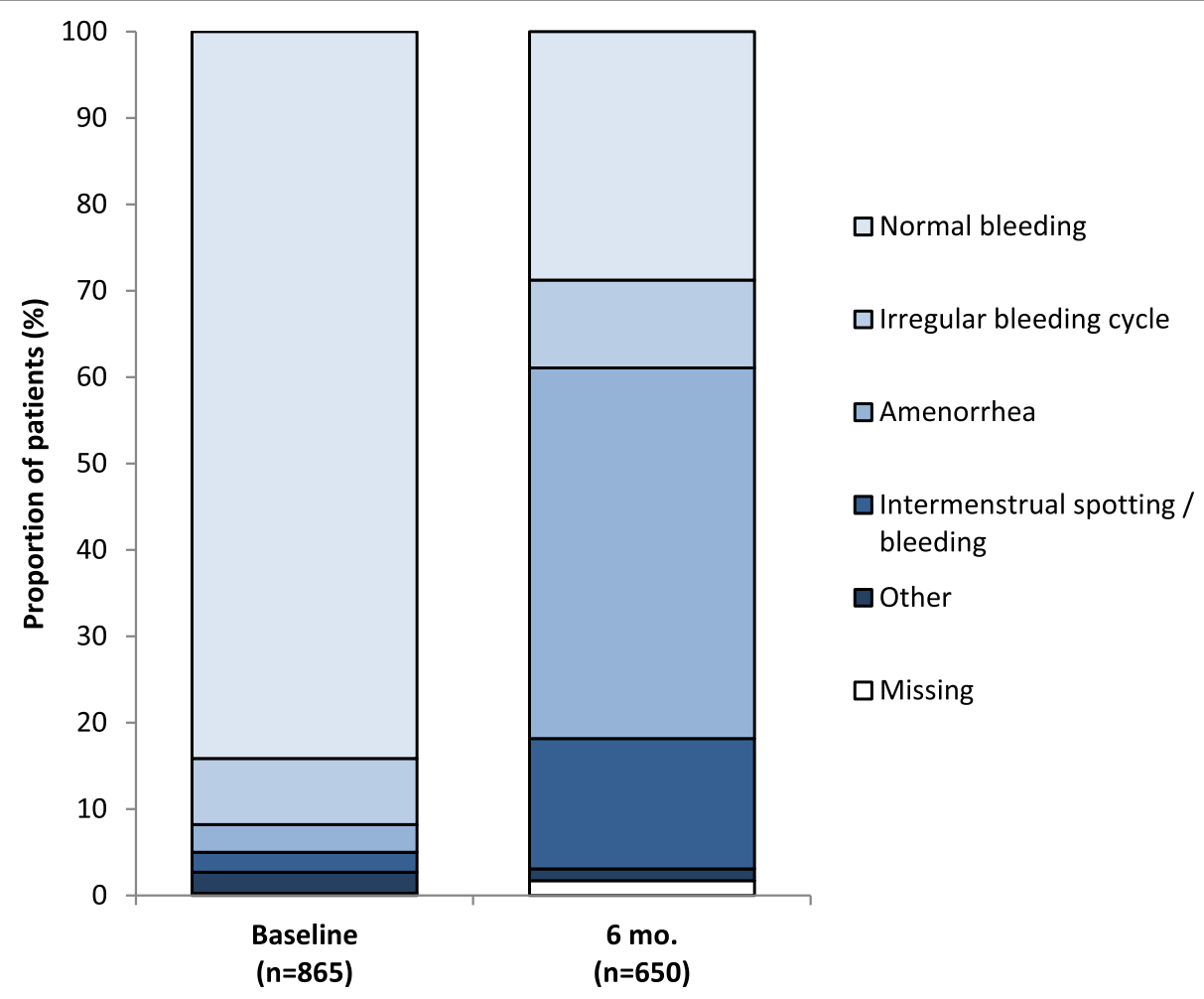

Fig. 3 Changes (\%) in the bleeding pattern from baseline to 6-months (6 mo.) visits. The bleeding patterns were defined as follows: 1) Normal bleeding: Regular bleeding with normal flow and duration. 2) Irregular bleeding cycle: Bleeding cycle less than 21 days or more than 35 days. 3 ) Amenorrhea: No menstruation during last 90 days. 4) Intermenstrual spotting / bleeding: Irregular episodes of bleeding, often light and short, occurring between otherwise fairly normal menstrual periods. Normal bleeding decreased from $84.2 \%$ at baseline to $28.8 \%$ after 6 months. Irregular bleeding cycle increased from 7.6 to $10.2 \%$, amenorrhea from 3.2 to $42.9 \%$, intermenstrual bleeding/spotting from 2.3 to $15.1 \%$. 
as the mean change \pm SD of $-5.6 \pm 3.3(n=42)$ and consequent improvement rate of $93.0 \%(n=40 / 43)$ marginally exceeded the mean change of the total population. Finally, the previous surgical or hormonal treatment did not affect the extent of EAPP change following dienogest administration (Table 4).

With regard to the bleeding profile of the patients, normal bleeding was decreased from $84.2 \%(n=728 /$ $865)$ to $28.8 \%(n=187 / 865)$ after 6 months, whereas amenorrhea increased from $3.2 \%(n=28 / 865)$ to $42.9 \%$ $(n=279 / 865)$, as displayed in Fig. 3.

A large proportion of patients $(66 \% ; n=322 / 488)$ and physicians $(66.8 \% ; n=326 / 488)$ were satisfied with the therapy. Perceivable overall symptom improvement was reported by $52.1 \%(n=254 / 488)$ of cases. Finally, the majority of patients continued treatment with dienogest $(88.1 \% ; n=430 / 488)$ after 6 months.

\section{Safety variables}

In total, there were nine serious adverse events (SAEs) reported in eight patients (Table 5). Thereof, anaemia (2/9 events) represented the most common. In eight cases the reason for seriousness was "Hospitalization necessary or prolonged", in the remaining case "Important medical event". All SAEs were recovered or resolved. Drug-related TEAEs were documented for 272 of 865 patients (31.5\%), with amenorrhea (5.9\%), metrorrhagia (5.1\%) and vaginal haemorrhage $4.5 \%)$ representing the most common. A minority of patients $(n=45 / 865 ; 5.2 \%)$ discontinued dienogest therapy due to drug-related TEAEs. Abnormal uterine bleeding (preferred terms: vaginal haemorrhage, menorrhagia and metrorrhagia) was the most prominent reason for discontinuation $(0.9 \% ; n=8 / 865)$. TEAEs irrespective of causality were

Table 5 All documented serious adverse events (to be placed after line 309)

\begin{tabular}{|c|c|c|c|c|}
\hline \multirow{2}{*}{$\begin{array}{l}\text { Serious Adverse } \\
\text { Event (MedDRA } \\
\text { PT) }\end{array}$} & \multicolumn{2}{|c|}{ Events } & \multicolumn{2}{|c|}{ Patients } \\
\hline & $\mathrm{n}$ & $\%$ & $\mathrm{n}$ & $\%$ \\
\hline Anaemia & 2 & 22.22 & 2 & 0.23 \\
\hline Bartholin's abscess & 1 & 11.11 & 1 & 0.12 \\
\hline Leptospirosis & 1 & 11.11 & 1 & 0.12 \\
\hline Peritonitis & 1 & 11.11 & 1 & 0.12 \\
\hline Dysmenorrhoea $^{a}$ & 1 & 11.11 & 1 & 0.12 \\
\hline Menorrhagia $^{a}$ & 1 & 11.11 & 1 & 0.12 \\
\hline Ovarian cyst & 1 & 11.11 & 1 & 0.12 \\
\hline Not coded yet ${ }^{b}$ & 1 & 11.11 & 1 & 0.12 \\
\hline Any PT & - & - & 8 & 0.96 \\
\hline Total & 9 & 100.00 & 865 & 100.00 \\
\hline
\end{tabular}

${ }^{a}$ Drug-related serious adverse events. ${ }^{b}$ not coded until cut-off date. FAS full analysis set, MedDRA Medical Dictionary for Regulatory Activities; PT preferred term documented in $35.5 \%$ of patients $(n=307 / 865)$ and were predominantly of mild-to-moderate intensity. Most common TEAEs are presented in Table 6.

\section{Discussion}

The debilitating, chronic and relapsing nature of endometriosis points to an unmet need for effective treatment approaches [10]. A study on women's pain revealed that $40 \%$ of women with endometriosis are dissatisfied with their current treatment, supportive of the fundamental necessity to improve the long-term management of debilitating pain and consequently, of HRQoL [21]. Importantly, endometriosis represents an economic and social burden on both families and society. Delayed diagnosis, high hospitalization, surgical procedures and impaired HRQoL are outcomes from the variable and chronic presentation of endometriosis symptoms [10]. Interestingly, several studies point to a higher prevalence of endometriosis in Asian women [35]. Particularly in low resource settings, the management of endometriosis should ideally be incorporated into the primary health care of women. Therefore, first-line medical therapy should focus on feasible drugs with favorable efficacy as well as long-term safety and tolerability profile. Dienogest has been extensively studied in four key European regulatory Phase II and III trials, as well as in numerous clinical trial programs performed in Europe and Asia [10, 15, 22]. More precisely, $2 \mathrm{mg}$ dienogest once daily demonstrated significant efficacy for lesion reduction and reduction in pain intensity as well as convincing safety and tolerability data $[15,22]$. Two large trials with treatment duration of 52 and 65 weeks concluded that dienogest is suitable for an effective long-term management of endometriosis, as it was associated with sustained reduction of pain intensity, predictable adverse events and in turn low discontinuation

Table 6 Incidences and rates of most frequent adverse events (i.e., at least $2 \%$ of patients), FAS (to be placed after line 309)

\begin{tabular}{|c|c|c|c|c|}
\hline \multirow{2}{*}{$\begin{array}{l}\text { Adverse Event } \\
\text { (MedDRA PT) }\end{array}$} & \multicolumn{2}{|c|}{ Events } & \multicolumn{2}{|c|}{ Patients } \\
\hline & $n$ & $\%$ & $n$ & $\%$ \\
\hline Amenorrhoea & 69 & 12.08 & 58 & 6.71 \\
\hline Metrorrhagia & 69 & 12.08 & 51 & 5.90 \\
\hline Vaginal haemorrhage & 41 & 7.18 & 39 & 4.51 \\
\hline Menstruation irregular & 28 & 4.90 & 25 & 2.89 \\
\hline Headache & 27 & 4.73 & 27 & 3.12 \\
\hline Acne & 20 & 3.50 & 20 & 2.31 \\
\hline Alopecia & 18 & 3.15 & 18 & 2.08 \\
\hline Weight increased & 17 & 2.98 & 17 & 1.97 \\
\hline Total $^{a}$ & 571 & 100.00 & 865 & 100.00 \\
\hline
\end{tabular}

${ }^{a} 67$ events were not coded until cut-off date. FAS full analysis set, MedDRA Medical Dictionary for Regulatory Activities; PT preferred term. Order of illustration is based on the frequency of events 
rates. Notably, beneficial effects on quality of life could be observed for up to 1 year [10].

Accordingly, our data suggest that dienogest might represent an option in the treatment of endometriosis in Asian women in the real-life setting, particularly in the improvement of HRQoL. As such, nominal improvements throughout all domains of the EHP-30 questionnaire after 6 months compared to baseline were observed. The most striking change was documented in the domain of pain, where an improvement in $78.4 \%$ of patients after 6 months was documented. Importantly, the changes in the other core scores were in line with changes in the domains of the modular questionnaire, underscoring the relevance to relieve pain for the improvement of all aspects of HRQoL. As some aspects of QoL such as social support and self-image might be affected through other psychosocial factors than EAPP, these domains appeared to be less influenced by dienogest. With regard to the EAPP, dienogest therapy was associated with a change of pain after 6 months, and an improvement rate of $84.3 \%$. Women with higher EAPP score $>4$ at baseline visit described greater improvement $(92.5 \%)$ at 6-months visit, in contrast to $71.3 \%$ improvement in women with low baseline severity of EAPP $\leq 4$.

According to recent guidelines, endometriosis should be classified with questions about pelvic pain and infertility in low resource settings in order to prescribe the most successful treatment possible prior to or even without definite surgical/histological confirmation [23]. Thus, early medical treatment without histological confirmation is endorsed [7]. A relevant proportion (28.6\%) of women enrolled in our study was exclusively clinically diagnosed, and, moreover, our baseline data indicate a delayed diagnosis after appearance of the first endometriosis symptoms in $37 \%$ of women. Moreover, women with surgical diagnosis appeared to be somewhat earlier diagnosed than clinically only diagnosed women. Interestingly, dienogest showed comparable effectiveness to reduce EAPP in women with surgical and clinical diagnosis in our study. This finding might be of significance for the clinical practice especially in low resource settings where patients do not have access to surgical facilities or need to delay surgery for medical or personal reasons.

The bleeding profile was affected by dienogest therapy, with decreased normal bleeding $(28.8 \%)$ and increased amenorrhea $(42.9 \%)$ after 6 months. Commonly, abnormal uterine bleeding is a well-known adverse event upon long-term treatment with progestins. A pooled analysis of clinical trials revealed that amenorrhea increased from $<5$ to $30 \%$ upon extended treatment duration, whereas undesirable patterns such as abnormal, frequent or prolonged bleeding decreased [10, 14-16, 24]. This highlights the importance of informing the patients about the potential adverse events in order to sustain adherence to therapy. As the overall discontinuation rate within this study was low (10.7\%), with no discontinuation due to amenorrhea, and eight discontinuations due to abnormal uterine bleeding, we assume that the changes in the bleeding patterns were tolerated well by the patients. In accordance with data from other studies, we observed mild-to-moderate drug-related TEAEs with amenorrhea and metrorrhagia being the most common. One of the two patients with drug-related SAEs (menorrhagia) had reported adenomyosis as concomitant disease which could be considered as causal factor of the SAE as well. Nevertheless, both drug-related SAEs as well as the majority of all drug-related AEs were recovered and the associated discontinuation rate was low (5.2\%), with overall seven discontinuations due to abnormal bleeding, one among them for metrorrhagia and menorrhagia, respectively, and six discontinuations due to vaginal haemorrhage. Taken together, safety of dienogest in Asian women with endometriosis is comparable to the existent observations in other countries [14-16].

This international non-interventional study design allows observing dienogest use among different Asian countries under real-world clinical settings for the first time. Therefore, all decisions in terms of diagnostic procedures and management of the disease are fully dependent on mutual agreement between the patient and the treating physician, without interference by a sponsor. As discussed above, there is an unmet need to improve the impaired quality of life of women with endometriosis, highlighting the clinical relevance of the study. A potential limitation of this study was the low number of evaluable patients included in the EFF, resulting from a lower feasibility of regular participation for many patients in the real-world setting. The local conditions at the participating sites possibly hampered the women to comply with the scheduled time points. Furthermore, there were certainly differences between the healthcare systems of the participant countries, in particular in terms of diagnosis and treatment. The major limitation of this study however is that within a single arm design lacking appropriate controls, the effects on HRQoL and safety cannot be fully attributed to the dienogest therapy. Other unknown factors might be underestimated and therefore, effectiveness and safety of dienogest can only be interpreted to a limited extent and requires further investigation.

\section{Conclusion}

In conclusion, our data indicated that therapy with dienogest could improve HRQoL and change the perception of EAPP in Asian women suffering from debilitating endometriosis symptoms. As no new safety signals were observed and a good satisfaction rate and 
compliance was achieved, dienogest might be an interesting therapeutic option for the long-term management of endometriosis among Asian women.

\section{Abbreviations}

EAPP: Endometriosis-associated pelvic pain; EFF: Efficacy analysis set; EHP30: Endometriosis Health Profile-30; FAS: Full analysis set; GnRH: Gonadotropin-releasing hormone; HRQoL: Health-related quality of life; NRS: Numeric rating scale; SAE: Serious adverse event.; TEAE: Treatmentemergent adverse event

\section{Acknowledgements}

The authors would like to thank all sites and patients who participated in the study as well as their responsible investigators. Medical writing support was provided by Sandra Baumgart of Alcedis GmbH, Giessen, Germany.

\section{Funding}

This study including its design, and the collection, analysis and interpretation of the data, as well as medical writing assistance for preparation of this manuscript was funded by Bayer AG.

\section{Availability of data and materials}

The datasets analyzed are available according to Bayer's policy on sharing clinical study data (https://www.clinicalstudydatarequest.com/StudySponsors/Study-Sponsors-Bayer.aspx).

\section{Authors' contributions}

SS developed the study protocol, conceptualized and designed the study, was responsible for study supervision and critically reviewed the manuscript. CA contributed to the data analysis and interpretation and to the study design, and critically reviewed the manuscript. KT, AH, RS, MJB, MK, SJS, ST and BSL helped to draft the manuscript and were responsible for data collection and implementation of the study at the respective sites. BSL was the principal investigator who helped to conceptualize the study and was responsible for supervision of the study. All authors were involved in revising the manuscript for important intellectual content and approved the final manuscript.

\section{Ethics approval and consent to participate}

The Food and Drug Administration, Department of Health, Republic of the Philippines approved the study protocol and all relevant study documents prior to study start. Ethical approval was obtained from each participating site of the Philippines (St. Luke's Medical Center; University of the East Ramon Magsaysay Memorial Medical Center; University of Santo Tomas Hospital), Thailand (Faculty of Medicine Siriraj Hospital; Faculty of Medicine Vajra Hospital; Faculty of Medicine Chiang Mai University; Faculty of Medicine Ramathibodi Hospital, Mahidol University; Maharat Nakhon Ratchasima Hospital) and Korea (CHA Gangnam Medical Center, CHA University; Keimyung University Dongsan Hospital; ChungNam National University Hospital; Inha University Hospital; The Catholic University Of Korea, Seoul St. Mary's Hospital; Seoul National University Hospital; Korea University Anam Hospital Clinical Trial Center; Ajou University Hospital; Severance Hospital Clinical Trial Center; ChonNam National University Hospital; Pusan National University Yangsan Hospital; GangNam Severance Hospital). Centralized ethical approval for participating sites was obtained for Singapore (SingHealth), Malaysia (Ministry of Health) and Indonesia (Faculty of Medicine University of Indonesia). Enrolled patients gave written informed consent prior to any study-related procedure.

\section{Consent for publication}

Not applicable.

\section{Competing interests}

CA is a current employee of Bayer AG, Berlin, Germany and SS is a former employee of Bayer AG. All other authors declare no competing interests.

\section{Publisher's Note}

Springer Nature remains neutral with regard to jurisdictional claims in published maps and institutional affiliations.

\section{Author details}

'Department of Obstetrics and Gynecology, Gynecologic Endocrinology Unit, Faculty of Medicine, Siriraj Hospital, Mahidol University, Bangkok, Thailand. ${ }^{2}$ Department of Obstetrics and Gynecology, Faculty of Medicine, Cipto Mangunkusumo National Central General Hospital, Jakarta, Indonesia. ${ }^{3}$ Department of Obstetrics and Gynecology, Sabah Women's and Children's Hospital, Kota Kinabalu, Malaysia. ${ }^{4}$ Department of Obstetrics and Gynecology Reproductive Endocrinology and Fertility, St. Luke's Medical Center, Philippine General Hospital, Metro Manila, Philippines. ${ }^{5}$ Department of Obstetrics and Gynecology, The Catholic University Of Korea, Seoul St. Mary's Hospital, Seoul, Korea. ${ }^{6}$ Department of Obstetrics and Gynecology, CHA Gangnam Medical Center, CHA University, Seoul, Korea. ${ }^{7}$ Department of Obstetrics and Gynecology, Hermina Pandanaran Hospital, Semarang, Indonesia. ${ }^{8}$ Bayer Pharma AG, Wuppertal, Germany. ${ }^{9}$ Former employee of Bayer AG, Seoul, Republic of Korea. ${ }^{10}$ Division of Gynecologic Endocrinology and Infertility, Department of Obstetrics and Gynecology, Severance Hospital,Yonsei University, 50-1 Yonsei-ro, Seodaemun-gu, 120-752 Seoul, Republic of Korea.

Received: 23 January 2019 Accepted: 17 April 2019

Published online: 16 May 2019

\section{References}

1. Kennedy S, Bergqvist A, Chapron C, D'Hooghe T, Dunselman G, Greb R, et al. ESHRE guideline for the diagnosis and treatment of endometriosis. Hum Reprod. 2005;20(10):2698-704.

2. Gerlinger C, Faustmann T, Hassall JJ, Seitz C. Treatment of endometriosis in different ethnic populations: a meta-analysis of two clinical trials. BMC Womens Health. 2012;12:9.

3. Arumugam K, Templeton AA. Endometriosis and race. Aust N Z J Obstet Gynaecol. 1992;32(2):164-5.

4. Yamamoto A, Johnstone EB, Bloom MS, Huddleston HG, Fujimoto WY. A higher prevalence of endometriosis among Asian women does not contribute to poorer IVF outcomes. J Assist Reprod Genet. 2017;34(6):765-74.

5. Sangi-Haghpeykar H, Poindexter AN 3rd. Epidemiology of endometriosis among parous women. Obstet Gynecol. 1995;85(6):983-92.

6. Dunselman GA, Vermeulen N, Becker C, Calhaz-Jorge C, D'Hooghe T, De Bie $B$, et al. ESHRE guideline: management of women with endometriosis. Hum Reprod. 2014;29(3):400-12.

7. Johnson NP, Hummelshoj L. Consensus on current management of endometriosis. Hum Reprod. 2013;28(6):1552-68.

8. Hirsch M, Begum MR, Paniz E, Barker C, Davis CJ, Duffy J. Diagnosis and management of endometriosis: a systematic review of international and national guidelines. BJOG. 2018;125(5):556-64.

9. Dai Y, Li X, Shi J, Leng J. A review of the risk factors, genetics and treatment of endometriosis in Chinese women: a comparative update. Reprod Health. 2018;15(1):82

10. Schindler AE. Dienogest in long-term treatment of endometriosis. Int J Women's Health. 2011;3:175-84.

11. Guo SW. Recurrence of endometriosis and its control. Hum Reprod Update. 2009;15(4):441-61.

12. Cheong Y, Tay P, Luk F, Gan HC, Li TC, Cooke I. Laparoscopic surgery for endometriosis: how often do we need to re-operate? J Obstet Gynaecol. 2008;28(1):82-5.

13. Luciano DE, Luciano AA. Management of endometriosis-related pain: an update. Womens Health (Lond). 2011;7(5):585-90.

14. Kohler G, Faustmann TA, Gerlinger C, Seitz C, Mueck AO. A dose-ranging study to determine the efficacy and safety of 1,2 , and $4 \mathrm{mg}$ of dienogest daily for endometriosis. Int J Gynaecol Obstet. 2010;108(1):21-5.

15. Strowitzki T, Faustmann T, Gerlinger C, Schumacher U, Ahlers C, Seitz C. Safety and tolerability of dienogest in endometriosis: pooled analysis from the European clinical study program. Int J Women's Health. 2015;7:393-401.

16. Strowitzki T, Faustmann T, Gerlinger C, Seitz C. Dienogest in the treatment of endometriosis-associated pelvic pain: a 12-week, randomized, doubleblind, placebo-controlled study. Eur J Obstet Gynecol Reprod Biol. 2010; 151(2):193-8.

17. Jones $G$, Jenkinson $C$, Kennedy $S$. Evaluating the responsiveness of the endometriosis health profile questionnaire: the EHP-30. Qual Life Res. 2004; 13(3):705-13.

18. Jones G, Jenkinson C, Taylor N, Mills A, Kennedy S. Measuring quality of life in women with endometriosis: tests of data quality, score reliability, 
response rate and scaling assumptions of the endometriosis health profile questionnaire. Hum Reprod. 2006;21(10):2686-93.

19. Jones G, Kennedy S, Barnard A, Wong J, Jenkinson C. Development of an endometriosis quality-of-life instrument: the endometriosis health Profile-30. Obstet Gynecol. 2001;98(2):258-64.

20. Vercellini P, Somigliana E, Consonni D, Frattaruolo MP, De Giorgi O, Fedele L. Surgical versus medical treatment for endometriosis-associated severe deep dyspareunia: I. effect on pain during intercourse and patient satisfaction. Hum Reprod. 2012;27(12):3450-9.

21. Bernuit D, Ebert AD, Halis G, Strothmann A, Gerlinger C, Geppert K, et al. Female perspectives on endometriosis: findings from the uterine bleeding and pain women's research study. J Endometriosis. 2011;3(2):73-85.

22. Lang J, Yu Q, Zhang S, Li H, Gude K, von Ludwig C, et al. Dienogest for treatment of endometriosis in Chinese women: a placebo-controlled, randomized, double-blind phase 3 study. J Women's Health (Larchmt). 2018; 27(2):148-55.

23. Johnson NP, Hummelshoj L, Adamson GD, Keckstein J, Taylor HS, Abrao MS, et al. World endometriosis society consensus on the classification of endometriosis. Hum Reprod. 2017;32(2):315-24.

24. Petraglia F, Hornung D, Seitz C, Faustmann T, Gerlinger C, Luisi S, et al. Reduced pelvic pain in women with endometriosis: efficacy of long-term dienogest treatment. Arch Gynecol Obstet. 2012;285(1):167-73.

Ready to submit your research? Choose BMC and benefit from:

- fast, convenient online submission

- thorough peer review by experienced researchers in your field

- rapid publication on acceptance

- support for research data, including large and complex data types

- gold Open Access which fosters wider collaboration and increased citations

- maximum visibility for your research: over $100 \mathrm{M}$ website views per year

At $\mathrm{BMC}$, research is always in progress.

Learn more biomedcentral.com/submissions 